\title{
Genetic Parameters for Claw Disorders in Dutch Dairy Cattle and Correlations with Conformation Traits
}

\author{
E. H. van der Waaij, ${ }^{1,2}$ M. Holzhauer, ${ }^{3}$ E. Ellen, ${ }^{2}$ C. Kamphuis, ${ }^{2}$ and G. de Jong ${ }^{4}$ \\ ${ }^{1}$ Department of Farm Animal Health, Veterinary Faculty, University of Utrecht, The Netherlands \\ ${ }^{2}$ Animal Breeding and Genetics Group, Wageningen University and Research Centre, The Netherlands \\ ${ }^{3} \mathrm{GD}$ Ltd., Deventer, The Netherlands \\ ${ }^{4}$ NRS (Royal Dutch Cattle Syndicate), Arnhem, The Netherlands
}

\begin{abstract}
Impaired claw health is one of the major problems causing production loss and reduced animal welfare in dairy cattle. In response, the Dutch Animal Health Service (GD) Ltd. initiated this study, in which claws of lactating and near-term cows and heifers in 430 herds were trimmed by hoof trimmers and the health status of the rear claws recorded. Only herds with $>75 \%$ of the animals having feet trimmed were considered, resulting in records on 21,611 animals. Eight claw disorders were scored: digital dermatitis (DD), interdigital dermatitis/heel horn erosions (IDHE), sole hemorrhage (SH), chronic laminitis (CL), sole ulcer (SU), white line disease (WLD), interdigital hyperplasia (HYP), and interdigital phlegmona (IP). The prevalence varied from $0.6 \%$ (IP) to $39.9 \%$ (SH). More than $70 \%$ of the animals had at least one claw disorder. Conformation traits and locomotion were recorded once during the animal's first lactation by trained classifiers of the Royal Dutch Cattle Syndicate and completely independent of the moment of claw trimming. Heritabilities were estimated using a sire model, and ranged from $<0.01$ (IP) to 0.10 (DD and HYP). Genetic correlations of incidences of claw disorders with locomotion were variable, ranging from $0.13(\mathrm{SH})$ to -0.91 (CL). Genetic correlations with the rear leg conformation traits were lower, ranging from 0.04 (ID with rear leg side view) to -0.69 (IP with rear leg rear view).
\end{abstract}

(Key words: genetic parameters, claw health, conformation)

Abbreviation key: $\mathbf{C L}=$ chronic laminitis, $\mathbf{D D}=$ digital dermatitis, HYP = interdigital hyperplasia, IDHE = interdigital dermatitis heel horn erosion, IP = interdigital phlegmona, $\mathbf{S H}=$ sole hemorrhage, $\mathbf{S U}=$ sole ulcer, WLD = white line disease.

Received February 25, 2005.

Accepted June 21, 2005.

Corresponding author: Liesbeth van der Waaij; e-mail: e.h. vanderwaaij@vet.uu.nl.

\section{INTRODUCTION}

Claw disorders are an important source of impaired welfare in Dutch dairy cattle. At present, over $70 \%$ of the animals have at least one claw disorder (our current research; Somers et al., 2003). The economic importance of claw disorders is considerable, with 25 to $30 \%$ of dairy cows treated per year across countries (Politiek et al., 1986; Smit et al., 1986; Boettcher et al., 1998), mainly near peak lactation (Blowey and Weaver, 1991).

The fact that claw disorders are an important cause of increased costs, substantial production loss (Green et al., 2002), increased calving interval (Collick et al., 1989; Barkema et al., 1994), and increased culling motivated the Dutch Animal Health Service Ltd. (GD) to investigate the possibility of improving the health status of claws. The herd book organization, Royal Dutch Cattle Syndicate (NRS), was interested in developing such a tool to evaluate the possibility of selecting for improved claw health.

Apart from improved herd management, claw health may be improved through selection. There are 2 main options: 1) selection on claw health using data that are currently not routinely collected; or 2) indirect selection on correlated conformation traits that are currently recorded. Successful indirect selection would require a substantial correlation between the conformation trait(s) and the most important claw disorders. In all cases, accurate genetic parameters are required. Although genetic parameters of claw disorders have been estimated previously (e.g., Smit et al., 1986; Reurink and van Arendonk, 1987; Baumgartner and Distl, 1988; Boelling et al., 2001), usually estimates have had low accuracy, been obtained for a limited number of disorders or parities, or both.

The aim of this research was to estimate genetic parameters for claw disorders, as well as correlations of claw disorders with conformation scores.

\section{MATERIALS AND METHODS}

\section{Data}

Claw health data were collected from 27,198 lactating or near-term cows and heifers by 39 professional claw 
trimmers during their normal visits to 466 Dutch dairy farms from May 2002 through October 2003. The presence (yes/no) of rear claw disorders [digital dermatitis (DD), interdigital dermatitis with heel horn erosions (IDHE), sole hemorrhage (SH), chronic laminitis (CL), sole ulcer (SU), white line disease (WLD), interdigital hyperplasia (HYP), and interdigital phlegmona (IP)] during the regular trimming of all dairy cows of the herd were registered. Symmetrical swelling of the dorsal coronary band, combined with an inflammation of the total interdigital space was defined as IP. The symptoms of inflammation of the caudal part of the interdigital space combined with a typical smell of "foot rot" defined IDHE. Other symptoms of IDHE were superficial horn defects or the typical layer structure of the horn of the bulbar region of the claws. Each cow was recorded only once, but some cows had more than one disorder, so that the total of prevalence records does not reflect the exact percentage of cows with a claw disorder.

For the analyses, the data were restricted to animals with at least $75 \%$ Holstein-Friesian (HF) genes, with known pedigree. In most cases, the claw trimmers trimmed the claws of all cows present, whether cows had previously noted problems. This better reflects the general claw health status of those herds. To create a data set representing this general claw health status of the herd, only herds where at least $75 \%$ of the cows were trimmed were considered in the analyses, resulting in 21,611 cows in 430 herds and descended from 3010 sires. After addition of pedigree data, 3729 sires were included in the analyses.

Conformation data are routinely recorded by trained classifiers of the Royal Dutch Cattle Syndicate on approximately $75 \%$ of the total number of animals during the first months of the first lactation. Every herd is visited every $8 \mathrm{mo}$ and all heifers in that herd at that moment, which were not scored yet, are scored for all conformation traits. Four traits related to feet and legs were included in the analyses: rear leg rear view, rear leg side view, foot angle, and a feet and legs index. The feet and legs index represents the set and bone quality of legs, quality of claws, and use of legs and feet. It is a descriptive trait used in The Netherlands to score the overall quality of the feet (claws) and legs. In addition, since 2002, locomotion has been scored as a linear trait and recorded on a less regular basis (as a research trait) on animals that are scored for conformation traits. The scoring system of the conformation traits is described in Table 1. The first 3 traits are official linear traits as defined by the World Holstein Friesian Federation.

In total, 15,364 cows with claw health scores from 425 herds also had a conformation score, and of those, 4469 cows had a locomotion score. These cows de-
Table 1. Description of the feet and leg traits considered.

\begin{tabular}{ll}
\hline Name & Score \\
\hline Rear leg set rear view ${ }^{1}$ & $1=$ hock in, $9=$ straight \\
Rear leg set side view $^{1}$ & $1=$ straight, $9=$ sickled \\
Foot angle & $1=$ low angle, $9=$ steep \\
Feet and legs & $70=$ poor, $89=$ very good \\
Locomotion $^{2}$ & $1=$ lame, $9=$ even gait, long strides \\
\hline
\end{tabular}

${ }^{1}$ For full description of the scoring system, see Hamoen (2003).

${ }^{2}$ Locomotion scores are defined as: 1 = lame, 2 = severe ab-/adduction present, uneven gait, short strides, $3=$ ab-/adduction present, uneven gait, 4 = slight ab-/adduction present, even gait, short strides, 5 = no ab-/adduction present, even gait, short strides, $6=$ slight ab- $/$ adduction present, even gait, medium strides, 7 = slight ab-/adduction present, even gait, long strides, $8=$ no ab-/adduction present, even gait, medium strides, and $9=$ no ab-/adduction present, even gait, long strides.

scended from 1184 sires, resulting in 1755 bulls after addition of pedigree records (sire and maternal grandsire). It is important to note that hoof trimming was performed completely independently from and on a different day than the conformation and locomotion recording.

\section{Statistical Analyses}

The binomial claw health data and the linearly scored conformation data were analyzed using a sire model and restricted maximum likelihood in ASREML (Gilmour et al., 2001). Heritabilities were estimated using a threshold model and linear approximation of the binary data. Correlations were obtained from bivariate analyses, applying a linear approximation to the binary claw health data, as ASREML was not able to estimate correlation between a binary and a linear trait. Different models were used for analyzing claw health and conformation traits. For claw health:

$$
\begin{gathered}
\mathrm{Y}_{\mathrm{ijklmnopq}}=\mu+\mathrm{P}_{\mathrm{i}}+\mathrm{L}_{\mathrm{j}}+\mathrm{B}_{\mathrm{k}} \\
+(\mathrm{H} \times \mathrm{D} \times \mathrm{T})_{l \mathrm{mn}}+\mathrm{a}_{\mathrm{o}}+\mathrm{e}_{\mathrm{ijk} \mathrm{kmnop}}
\end{gathered}
$$

where $\mathrm{Y}$ is one of the claw disorders, $\mu$ is the overall mean, $\mathrm{P}_{\mathrm{i}}$ is the fixed effect of the $i$ th parity ( $\mathrm{I}=1$ to 12), $L_{j}$ is the fixed effect of the $j$ th lactation stage at the time of trimming ( $\mathrm{j}=1$ to 15 ), where stage 1 is defined as $\mathrm{d} 1$ to 15 , the subsequent stages are $30 \mathrm{~d}$ each: stage 2 represents $d 16$ to 35, stage 3 represents d 36 to 65 , etc., and all animals with over $15 \mathrm{mo}$ in lactation are combined in stage $15, \mathrm{~B}_{\mathrm{k}}$ is the fixed effect of the $k$ th breed class ( $\mathrm{k}=1$ to 16 ), where class 1 consists of animals that are pure $\mathrm{HF}$ and the subsequent 15 classes consist of animals that are at least $75 \% \mathrm{HF}$ and consist of, at maximum, $25 \%$ of other breeds, $\mathrm{H}_{1} \times \mathrm{D}_{\mathrm{m}}$ $\times \mathrm{T}_{\mathrm{n}}$ is the interaction of the $l$ th herd with the $m$ th 
Table 2. Means, SD, minima, and maxima of claw health and conformation traits, and prevalence of the claw disorders.

\begin{tabular}{|c|c|c|c|c|c|}
\hline Trait $^{1}$ & $\begin{array}{l}\text { LS } \\
\text { Mean }^{2}\end{array}$ & SD & Minimum & Maximum & $\begin{array}{l}\text { Prevalence } \\
(\%)\end{array}$ \\
\hline \multicolumn{6}{|c|}{ Claw disorders } \\
\hline $\mathrm{SH}$ & 0.62 & 0.40 & 0 & 1 & 39.9 \\
\hline IDHE & 0.60 & 0.41 & 0 & 1 & 38.7 \\
\hline DD & 0.27 & 0.37 & 0 & 1 & 21.7 \\
\hline WLD & 0.11 & 0.28 & 0 & 1 & 9.6 \\
\hline HYP & 0.07 & 0.22 & 0 & 1 & 5.9 \\
\hline SU & 0.06 & 0.22 & 0 & 1 & 5.4 \\
\hline CL & 0.06 & 0.18 & 0 & 1 & 4.1 \\
\hline IP & 0.00 & 0.30 & 0 & 1 & 0.6 \\
\hline \multicolumn{6}{|c|}{ Conformation and locomotion } \\
\hline SV & 5.093 & 1.41 & 1 & 9 & \\
\hline RV & 4.896 & 1.53 & 1 & 9 & \\
\hline FA & 4.855 & 1.39 & 1 & 9 & \\
\hline LOC & 4.799 & 1.52 & 1 & 9 & \\
\hline FL & 80.34 & 2.98 & 70 & 89 & \\
\hline
\end{tabular}

${ }^{1} \mathrm{SH}=$ Sole hemorrhage, IDHE = interdigital dermatitis heel horn erosion, $\mathrm{DD}=$ digital dermatitis, WLD = white line disease, HYP = interdigital hyperplasia, $\mathrm{SU}=$ sole ulcer, $\mathrm{CL}=$ chronic laminitis, $\mathrm{RV}=$ rear leg rear view, $\mathrm{SV}=$ rear leg side view, $\mathrm{FA}=$ foot angle, $\mathrm{LOC}=$ locomotion, $\mathrm{FL}=$ feet and legs.

${ }^{2}$ LS Mean = least squares mean; mean corrected for the effects in the model.

scoring day and the $n$th claw trimmer, $\mathrm{a}_{0}$ is the random sire effect and $\mathrm{e}_{\mathrm{ijklmnop}}$ is the random error term.

For the conformation traits:

$\mathrm{Y}_{\mathrm{ijklmno}}=\mu+\mathrm{CS}_{\mathrm{i}}+\mathrm{B}_{\mathrm{j}}+\mathrm{A}_{\mathrm{k}}+(\mathrm{H} \times \mathrm{D})_{\mathrm{lm}}+\mathrm{a}_{\mathrm{n}}+\mathrm{e}_{\mathrm{ijklmno}}$

where $\mathrm{Y}$ is one of the conformation traits, $\mu$ is the overall mean, $\mathrm{CS}_{\mathrm{i}}$ is the fixed effect of the $i$ th conformation standard ( $\mathrm{I}=1$ to 2 , black and white and red and white), $\mathrm{B}_{\mathrm{j}}$ is the fixed effect of the $j$ th breed class $(\mathrm{j}=1$ to 16 ), $\mathrm{A}_{\mathrm{k}}$ is the fixed effect of the $k$ th age in months at the moment of scoring, $\mathrm{H}_{1} \times \mathrm{D}_{\mathrm{m}}$ is the interaction of the $l$ th herd with the $m$ th date of conformation scoring, $\mathrm{a}_{\mathrm{n}}$ is the random sire effect, and $\mathrm{e}_{\mathrm{ijk} k \mathrm{mno}}$ is the random error term. For both models, the relationship matrix was added using the sire and maternal grandsire.

\section{RESULTS}

Based on the fixed effect class estimates it can be concluded that the disorders IDHE, WLD, SU, and CL mainly occurred after the fourth parity. In addition, SH mainly occurred in the first part of the lactation, especially from the second until the fifth month. Table 2 has the corrected means, SD, minima, and maxima of the claw health and conformation scores. More than $70 \%$ of the animals had at least one disorder. Three disorders occurred frequently (SH, IDHE, and DD), so the information content of the data for those traits was reasonably high. The other traits occurred much less frequently, most likely because of environmental reasons, making it more difficult to estimate the genetic background of the trait. The prevalence of IP was so low $(0.6 \%)$ that it was left out of further analyses.

The heritability estimates using the threshold model and the linear approximation were very similar, which is why Table 3 only shows heritabilities, genetic, and phenotypic correlations among the claw disorders for the linear approximation. The traits are presented in order of prevalence. The heritabilities for the claw disorders were low and ranged from 0.01 (SU and CL) to 0.10 (DD). The genetic correlations ranged from -0.18 (DD with SU) to 1.16 (CL with SU). Most standard errors of the estimates were high resulting from the low prevalences of the disorders. The phenotypic correlations were low and ranged from -0.01 (WLD with IDHE) to 0.10 (WLD with SH). The residual correlations were very similar to the phenotypic correlations (results not shown).

The heritabilities and genetic and phenotypic correlations between the leg conformation traits are presented in Table 4. The heritabilities were higher than those for the claw disorders and ranged from 0.10 (locomotion) to 0.24 (feet and legs score). The genetic correlations ranged from -0.72 (rear leg side view with foot angle) to 0.98 (locomotion with feet and legs index). The phenotypic correlations ranged from -0.31 (feet and legs index with rear leg side view) to 0.85 (locomotion with feet and legs index). The residual correlations were very similar to the phenotypic correlations (results not shown).

The genetic correlations between the claw disorders and leg conformation traits are presented in Table 5. The correlations ranged from -0.67 (DD with locomo- 
Table 3. Heritabilities (diagonal) and genetic (above diagonal) and phenotypic correlations (below diagonal) among traits related to claw health (with SE).

\begin{tabular}{|c|c|c|c|c|c|c|c|}
\hline Trait $^{1}$ & IDHE & SH & DD & WLD & HYP & $\mathrm{SU}$ & CL \\
\hline IDHE & $0.05(0.01)$ & $0.13(0.17)$ & $0.74(0.09)$ & $0.12(0.20)$ & $0.67(0.09)$ & $-0.11(0.25)$ & $0.73(0.16)$ \\
\hline $\mathrm{SH}$ & $0.04(0.01)$ & $0.08(0.02)$ & $-0.12(0.16)$ & $0.30(0.21)$ & $0.13(0.16)$ & $0.81(0.26)$ & $0.63(0.21)$ \\
\hline DD & $0.11(0.01)$ & $0.01(0.01)$ & $0.10(0.02)$ & $0.08(0.20)$ & $0.47(0.12)$ & $-0.18(0.25)$ & $0.12(0.23)$ \\
\hline WLD & $-0.01(0.01)$ & $0.10(0.01)$ & $-0.01(0.01)$ & $0.02(0.01)$ & $0.34(0.18)$ & $0.95(0.15)$ & $0.33(0.28)$ \\
\hline HYP & $0.10(0.01)$ & $0.03(0.01)$ & $0.10(0.01)$ & $0.02(0.01)$ & $0.10(0.02)$ & $0.18 \quad(0.26)$ & $0.58(0.20)$ \\
\hline $\mathrm{SU}$ & $0.01(0.01)$ & $0.08(0.01)$ & $-0.00(0.01)$ & $0.09(0.01)$ & $0.05(0.01)$ & $0.01(0.01)$ & $1.16(0.25)$ \\
\hline CL & $0.07(0.01)$ & $0.01(0.01)$ & $0.01(0.01)$ & $0.07(0.01)$ & $0.06(0.01)$ & $0.06(0.01)$ & $0.01(0.01)$ \\
\hline
\end{tabular}

${ }^{1} \mathrm{IDHE}=$ Interdigital dermatitis heel horn erosion, $\mathrm{SH}=$ sole hemorrhage, $\mathrm{DD}=$ digital dermatitis, $\mathrm{WLD}=$ white line disease, HYP = interdigital hyperplasia, $\mathrm{SU}=$ sole ulcer, $\mathrm{CL}=$ chronic laminitis.

tion) to 0.82 (HYP with locomotion). In general, the genetic correlations between locomotion and the claw disorders were high, indicating that locomotion may be a good indicator for susceptibility to claw disorders. Foot angle has a high correlation with WLD. However, as foot angle is most likely a trait for which an optimum value exists, it is not obvious how to interpret this correlation. From the high genetic and phenotypic correlation between locomotion and feet and legs (Table 4), it was expected that the genetic correlations between claw disorders and these 2 traits would be of similar size. However, the estimates of the genetic correlations for both groups in most occasions were different, which may be ascribed to the large standard errors for the estimates.

Phenotypic correlations between the claw disorders and leg conformation traits are in Table 6 . These correlations were much lower than the corresponding genetic correlations in Table 5 and ranged from -0.18 (feet and legs with HYP) to 0.07 (rear leg side view with CL). Unlike the genetic correlations, only the phenotypic correlations between the claw disorders and rear leg side view were positive, all others were negative. Most likely, the conformation traits will have an optimum value relating to claw disorder susceptibility, although that cannot be deduced from this data set.

\section{DISCUSSION}

Results in this paper indicate that most of the claw disorders recorded are heritable, which is in agreement with previous studies (e.g., Reurink and van Arendonk, 1987; Pryce et al., 1997; Boettcher et al., 1998). Important reasons for the low heritabilities are the low prevalence as well as the large environmental influence (e.g., presence or absence of infection pressure, floor type, or food quality). Genetic correlations among the disorders and between the disorders and the conformation traits were generally high. All phenotypic correlations were considerably lower, again most likely mainly due to the low prevalences of the claw disorders. Based on the genetic correlations, locomotion seems a good indicator for claw disorder susceptibility.

An infectious disease that is very painful for the cow is IP. However, it disappears normally in a matter of days in response to antibiotic treatment. The prevalence rate as presented here is not necessarily representative of the magnitude of the problem. The trait $\mathrm{SH}$ is considered to be an indicator of subclinical laminitis and mainly occurred during the first 6 mo of the lactation, especially during the second until the fifth month (our unpublished results; Collard et al., 2000). This may be due to the inability of the cow to consume sufficient DM to meet the demands set by the high production level (Vermunt and Greenough, 1994), in combination with floor conditions (Webster, 2001, 2002; Somers et al., 2003; van der Tol, 2004) and changes in the support structures of the bovine hooves associated with calving (Tarlton et al., 2002). This can result in a decrease of the fat deposits in the claws, and, consequently, in an increased risk of bruising of the claw tissue between the pedal bone and the sole horn (Lischer et al., 2002).

Table 4. Heritabilities (diagonal) and genetic (above diagonal) and phenotypic (below diagonal) correlations among conformation traits (with SE).

\begin{tabular}{|c|c|c|c|c|c|}
\hline Trait $^{1}$ & RV & SV & FA & LOC & FL \\
\hline RV & $0.11(0.03)$ & $-0.12(0.15)$ & $0.26(0.14)$ & $0.70(0.14)$ & $0.79(0.07)$ \\
\hline SV & $-0.20(0.01)$ & $0.22(0.04)$ & $-0.72(0.07)$ & $-0.14 \quad(0.20)$ & $-0.36(0.10)$ \\
\hline FA & $0.31(0.01)$ & $-0.46(0.01)$ & $0.18(0.03)$ & $0.47(0.18)$ & $0.51(0.10)$ \\
\hline LO & $0.51(0.01)$ & $-0.20(0.01)$ & $0.32(0.01)$ & $0.10(0.04)$ & $0.98(0.02)$ \\
\hline FL & $0.56(0.01)$ & $-0.31(0.01)$ & $0.42(0.01)$ & $0.85(0.01)$ & $0.24(0.04)$ \\
\hline
\end{tabular}

${ }^{1} \mathrm{RV}=$ Rear leg rear view, $\mathrm{SV}=$ rear leg side view, $\mathrm{FA}=$ foot angle, $\mathrm{LOC}=$ locomotion, $\mathrm{FL}=$ feet and legs. 
Table 5. Genetic correlations (with SE) of some traits related to claw health with some conformation traits.

\begin{tabular}{lrlrlrr}
\hline Trait $^{1}$ & \multicolumn{1}{c}{ RV } & \multicolumn{1}{c}{ SV } & \multicolumn{1}{c}{ FA } & \multicolumn{1}{c}{ LOC } & \multicolumn{1}{c}{ FL } \\
\hline SH & $0.14(0.18)$ & $0.13(0.15)$ & $0.11(0.16)$ & $0.13(0.24)$ & $0.26(0.14)$ \\
IDHE & $-0.10(0.16)$ & $0.27(0.13)$ & $-0.31(0.14)$ & $-0.71(0.17)$ & $-0.24(0.13)$ \\
DD & $-0.21(0.15)$ & $0.16(0.13)$ & $-0.22(0.13)$ & $-0.67(0.19)$ & $-0.34(0.12)$ \\
WLD & $-0.12(0.21)$ & $-0.19(0.18)$ & $0.64(0.15)$ & $-0.04(0.31)$ & $0.01(0.18)$ \\
HYP & $-0.35(0.15)$ & $0.04(0.13)$ & $-0.15(0.14)$ & $0.82(0.12)$ & $-0.35(0.12)$ \\
SU & $-0.07(0.28)$ & $0.16(0.22)$ & $-0.05(0.24)$ & $-0.04(0.40)$ & $-0.31(0.26)$ \\
CL & $0.22(0.24)$ & $0.20(0.19)$ & $0.36(0.19)$ & $-0.91(0.18)$ & $-0.32(0.19)$ \\
\hline
\end{tabular}

${ }^{1} \mathrm{SH}=$ Sole hemorrhage, $\mathrm{IDHE}=$ interdigital dermatitis heel horn erosion, $\mathrm{DD}=$ digital dermatitis, $\mathrm{WLD}=$ white line disease, HYP = interdigital hyperplasia, $\mathrm{SU}=$ sole ulcer, $\mathrm{CL}=$ chronic laminitis, $\mathrm{RV}=$ rear leg rear view, $\mathrm{SV}=$ rear leg side view, $\mathrm{FA}=$ foot angle, $\mathrm{LOC}=$ locomotion, $\mathrm{FL}=$ feet and legs.

The possible response of the farmer to feed more concentrates to compensate for the energy shortage may result in a decrease in $\mathrm{pH}$ level in the rumen, which in turn results in a release of endotoxins, histamines, or a combination of both into the blood. The subsequent vasodilation will eventually result in damaged blood vessels in the claw. Disturbance of the circular blood supply of the corium may result in poor attachment of the horn to the pedal bone and poor horn production, thereby decreasing the horn quality and often permanently increasing its vulnerability (Politiek et al., 1986; Blowey and Weaver, 1991; Collard et al., 2000; Vermunt, 2000). Prolonged problems may then lead to dropping of the pedal bone. The pressure of this bone on the corium causes hemorrhages that become visible after 2 mo and are considered to be the precursor of typical sole ulcers (as reviewed by Nocek, 1997; Lischer et al., 2002). The trait WLD originates from hemorrhages and poor horn quality (related to laminitis) combined with an anatomical predisposition and environmental factors (Mülling, 2002). A sole ulcer is a continuous opening in the sole horn that exposes the corium. This may be a consequence of a sole hemorrhage.

In a sense, all these claw disorders are a consequence of metabolic and environmental stress, sometimes in combination with bacterial infections. Because changes to the pedal bone and the corium are more or less permanent, it is expected that the risk of getting a claw disor- der will increase over lactations. Indeed, results of the present study indicate that SU and WLD, and, to a lesser extent, CL, occur during the later parities. Hirst et al. (2002) have shown that in early lactations, a previously lame cow had a much higher risk of becoming lame again, both within and across lactations. Unfortunately, in the current data, only prevalences of the claw disorders were available. It would be worthwhile to follow a large cohort of cows across lactations, preferably for a lifetime performance, to gain more insight in the genetic background of relationships between (re)occurrence of claw disorders.

The previous information would suggest that there is a clear cause and consequence in the relation between, for example, SH and SU, and likely with CL. This would be in agreement with the high genetic correlation between $\mathrm{SH}$ and $\mathrm{CL}$ and $\mathrm{SU}$ shown here and previously (Manske et al., 2002). However, the relation between WLD and SH was less clear as they seem to develop from similar etiology. Enevoldsen et al. (1991) suggested that severe degrees of SU increased the risk of CL and IDHE. Although in this study, the genetic correlation between SU and CL is extremely high $(>1)$, it does not seem logical to consider SU as a risk factor as both disorders seem to originate from the same etiology (Lischer et al., 2002). In addition, in this study, the genetic correlation between IDHE and SU was not high $(-0.11)$. However, the genetic correlations between

Table 6. Phenotypic correlations (with SE) of some traits related to claw health with some conformation traits.

\begin{tabular}{llllll}
\hline Trait $^{1}$ & RV & SV & FA & LOC & FL \\
\hline SH & $-0.04(0.02)$ & $0.05(0.02)$ & $-0.04(0.02)$ & $-0.07(0.02)$ & $-0.07(0.02)$ \\
IDHE & $-0.02(0.02)$ & $0.05(0.02)$ & $-0.04(0.02)$ & $-0.04(0.02)$ & $-0.03(0.02)$ \\
DD & $-0.02(0.02)$ & $0.04(0.02)$ & $-0.03(0.02)$ & $-0.07(0.02)$ & $-0.07(0.02)$ \\
WLD & $-0.03(0.02)$ & $0.01(0.02)$ & $-0.01(0.02)$ & $-0.04(0.02)$ & $-0.03(0.02)$ \\
HYP & $-0.10(0.02)$ & $0.10(0.02)$ & $-0.14(0.02)$ & $-0.15(0.02)$ & $-0.18(0.02)$ \\
SU & $-0.06(0.02)$ & $0.05(0.02)$ & $-0.08(0.02)$ & $-0.10(0.02)$ & $-0.09(0.02)$ \\
CL & $-0.08(0.02)$ & $0.07(0.02)$ & $-0.05(0.02)$ & $-0.09(0.02)$ & $-0.09(0.02)$ \\
\hline
\end{tabular}

${ }^{1} \mathrm{SH}=$ Sole hemorrhage, IDHE = interdigital dermatitis heel horn erosion, $\mathrm{DD}=$ digital dermatitis, $\mathrm{WLD}=$ white line disease, HYP = interdigital hyperplasia, $\mathrm{SU}=$ sole ulcer, $\mathrm{CL}=$ chronic laminitis, $\mathrm{RV}=$ rear leg rear view, $\mathrm{SV}=$ rear leg side view, $\mathrm{FA}=$ foot angle, $\mathrm{LOC}=$ locomotion, $\mathrm{FL}=$ feet and legs. 
IDHE and CL (0.73) and HYP (0.67) in the present study were high, as in Manske et al. (2002). It can be argued that a change in claw shape due to CL combined with pressure-induced pain on the lateral claw might force the cow to distribute its weight to the medial claw. Consequently, an increased hock angle can be seen, which may make the claws more susceptible to IDHE or HYP (Enevoldsen et al., 1991; van der Tol et al., 2004).

Conformation is scored on a routine basis in a large percentage of the Dutch dairy cattle population during the first months of the first lactation. A large database is available with records on leg and udder traits. One aim of the present study was to identify traits that could serve as indicator traits for claw health, so that the actual claw disorders need be monitored. This would be cost efficient. Moreover, animals that are kept in an optimal environment and, consequently, are less exposed to factors that impair claw health, could still be monitored for their potential resistance to various claw disorders. Results in the present study suggest that locomotion scored during the first parity is a good indicator for future claw health, as also reported by Hirst et al. (2002). The conformation generally is scored during the first months of the first lactation. The highest frequency of claw disorders is seen in this period of lactation. Recording of locomotion during this period may indeed record the presence or absence of a claw disorder, and, consequently, the susceptibility to claw disorders in later life. In addition, there was no difference in the genetic correlations between the conformation traits and the claw disorder traits between firstparity and later-parity cows. In other words, time between observations of conformation and claw health had no influence on the size of the correlation. It should be noted that locomotion has only been scored for the past 2 yr. Consequently, of all animals with records on locomotion, the time between locomotion and claw health scoring was relatively short.

\section{CONCLUSIONS}

There is evidence that susceptibility to a number of claw disorders is heritable, although the heritability estimates would benefit from more data.

Locomotion seems to be a good indicator for developing claw disorders at later stage in life. Its worth should be validated in the future as more records will be available, as will records with locomotion scoring and hoof trimming multiple lactations apart. It is easy to measure, and thus, a cheap trait to score with a relatively high correlation to most claw disorders considered in this study. Further research is needed to confirm the present results, and to investigate to what extent selection could be successful without having to collect claw health data.

\section{ACKNOWLEDGMENTS}

We would like to thank the participating Dutch dairy farmers and the hoof trimmers for putting so much effort into collecting high quality data. The study was funded by the Dairy Commodity Board (Rijswijk, The Netherlands).

\section{REFERENCES}

Barkema, H. W., J. D. Westrik, K. A. S. van Keulen, Y. H. Schukken, and A. Brand. 1994. The effects of lameness on reproductive performance, milk production and culling in Dutch dairy farms. Prev. Vet. Med. 20:249-259.

Baumgartner, C., and O. Distl. 1988. Possible selection strategies to improve claw soundness by claw measurements. Paper presented at the EAAP working group "Claw Quality in Cattle" at Veldhoven, The Netherlands. EAAP, Rome, Italy.

Blowey, R. W., and A. D. Weaver. 1991. Pages 89-128 in Diseases and Disorders of Cattle. Wolfe Publishing Ltd., Aylesbury, UK.

Boelling, D., P. Madsen, and J. Jensen. 2001. Genetic parameters of foot and leg traits in future AI bulls. II. Correlation to body conformation traits in daughters. Acta Agric. Scand. A Anim. Sci. 51:122-128.

Boettcher, P. J., J. C. M. Dekkers, L. G. Warnick, and S. J. Wells. 1998. Genetic analysis of clinical lameness in dairy cattle. J. Dairy Sci. 81:1148-1156.

Collard, B. L., P. J. Boettcher, J. C. M. Dekkers, D. Petitclerc, and L. R. Schaeffer. 2000. Relationships between energy balance and health traits of dairy cattle in early lactation. J. Dairy Sci. 83:2683-2690.

Collick, D. W., W. R. Ward, and H. Dobson. 1989. Association between types of lameness and fertility. Vet. Rec. 125:103-106.

Enevoldsen, C., Y. T. Grohn, H. Schukken, and I. Thysen. 1991. Heel erosion and other interdigital disorders in dairy cows: Associations with season, cow characteristics, disease, and production. J. Dairy Sci. 74:1299-1309.

Gilmour, A. R., B. R. Cullis, S. J. Welham, and R. Thompson. 2001. ASREML Reference Manual. NSW Agriculture, Orange, Australia.

Green, L. E., V. J. Hedges, Y. H. Schukken, R. W. Blowey, and A. J. Packington. 2002. The impact of clinical lameness on the milk production of dairy cows. J. Dairy Sci. 85:2250-2256.

Hamoen, A. 2003. International type evaluation of dairy cattle. Proc. 6th World Classifiers' Workshop, St-Hyacinthe, Canada.

Hirst, W. M., R. D. Murray, W. R. Ward, and N. P. French. 2002. A mixed-effects time-to-event analysis of the relationship between first-lactation lameness and subsequent lameness in dairy cows in the UK. Prev. Vet. Med. 54:191-201.

Lischer, C. J., P. Ossent, M. Räber, and H. Geyer. 2002. Suspensory structures and supporting tissues of the third phalanx of cows and their relevance to the development of typical sole ulcers (Rusterholz ulcers). Vet. Rec. 151:694-698.

Manske, T., J. Hultgren, and C. Bergsten. 2002. Prevalence and interrelationships of claw lesions and lameness in Swedish dairy cows. Prev. Vet. Med. 54:247-263.

Mülling, Ch. K. W. 2002. Theories on the pathogenesis of white line disease-An anatomical perspective. Pages 90-98 in Proc. 12th Int. Symp. Disorders Rumin. Digit, Orlando, FL.

Nocek, J. E. 1997. Bovine acidosis: Implications on laminitis. J. Dairy Sci. 80:1005-1028.

Politiek, R. D., O. Distl, T. Fjeldaas, J. Heeres, B. T. McDaniel, E. Nielsen, D. J. Peterse, A. Reurink, and P. Strandberg. 1986. Importance of claw quality in cattle: Review and recommendations to achieve genetic improvement. Report to the EAAP working group on claw quality in cattle. Livest. Prod. Sci. 15:133-152. 
Pryce, J. E., R. F. Veerkamp, R. Thompson, W. G. Hill, and G. Simm. 1997. Genetic aspects of common health disorders and measures of fertility in Holstein-Friesian dairy cattle. Anim. Sci. 65:353360.

Reurink, A., and J. A. M. van Arendonk. 1987. Relationships of claw disorders and claw measurements with efficiency of production in dairy cattle. Polycopy, 38th Mtg. of EAAP, Lisbon, Portugal. EAAP, Rome, Italy.

Smit, H., B. Verbeek, D. J. Peterse, B. T. McDaniel, and R. D. Politiek. 1986. Genetic aspects of claw disorders, claw measurements and 'type' scores for feet in Friesian cattle. Livest. Prod. Sci. 15:205.

Somers, J. G. J. C., K. Frankena, E. N. Noordhuizen-Stassen, and J. H. M. Metz. 2003. Prevalence of claw disorders in Dutch dairy cows exposed to several floor systems. J. Dairy Sci. 86:2082-2093.

Tarlton, J. F., D. E. Holah, K. M. Evans, S. Jones, G. R. Pearson, and A. J. F. Webster. 2002. Biomechanical and histopathological changes in the support structures of bovine hooves around the time of first calving. Vet. J. 163:196-204.

van der Tol, P. P. J., S. S. van der Beek, J. H. M. Metz, E. N. Noordhuizen-Stassen, W. Back, C. R. Braam, and W. A. Weijs. 2004. The effect of preventive trimming on weight bearing and force balance on the claws of dairy cattle. J. Dairy Sci. 87:1732-1738.

Vermunt, J. J. 2000. Risk factors of laminitis—an overview. Pages 3435 in Proc. 11th Int. Symp. Disorders Rumin. Digit. Parma, Italy.

Vermunt, J. J., and P. R. Greenough. 1994. Predisposing factors of laminitis in cattle. Br. Vet. J. 150:151-164.

Webster, A. J. F. 2001. Effects of housing and feed dry matter concentration on the development of claw horn lesions in dairy cows at first calving and in first lactation. Vet. J. 162:56-65.

Webster, A. J. F. 2002. Effects of housing practices on the development of foot lesions in dairy heifers at early lactation. Vet. Rec. 151:9-12. 